\title{
How research on language evolution contributes to linguistics
}

\author{
Przemysław Żywiczyński \\ Nicolaus Copernicus University, Toruń \\ przemek@umk.pl
}

\begin{abstract}
Since its inception in the second part of the 20th century, the science of language evolution has been exerting a growing and formative pressure on linguistics. More obviously, given its interdisciplinary character, the science of language evolution provides a platform on which linguists can meet and discuss a variety of problems pertaining to the nature of language and ways of investigating it with representatives of other disciplines and research traditions. It was largely in this way that the attention of linguists was attracted to the study of emerging sign languages and gestures, as well as to the resultant reflection on the way different modalities impact communicative systems that use them. But linguistics also benefits from the findings made by language evolution researchers in the context of their own research questions and methodologies. The most important of these findings come out of the experimental research on bootstrapping communication systems and the evolution of communicative structure, and from mass comparison studies that correlate linguists data with a wide range of environmental variables.
\end{abstract}

Keywords: The science of language evolution; sign linguistics and gesture studies; cultural evolution; Linguistic Niche Hypothesis; nomothetic research.

\section{Introduction}

The science of language evolution (SLE) is an interdisciplinary research area that investigates the emergence of language in our phylogeny and general processes of language diversification and language change (see e.g. Żywiczyński 2018 for the scope of SLE's history and the scope of its research). To address evolutionary questions, SLE researchers take a very broad perspective on language and language-related phenomena. Apart from covering core linguistic topics (such as language change, typology or acquisition), they need to, for example, take into consideration the anatomical, neural and cognitive prerequisites for language and communication in general (see Section 2 below), study sys- 
tems of non-human communication and cognition; or be familiar with the evolutionary history of species (see Christiansen and Kirby 2003 and Section 8 below). In effect, SLE can exert two types of influence on linguistics. Given its interdisciplinary character, it provides a platform on which linguists can meet and discuss a variety of problems pertaining to the nature of language, and ways of investigating it, with representatives of other disciplines and research traditions. In this way, SLE can help generate a new quality in the study of language, based on a new range of research questions, data and methodologies. At the same time, linguistics can also benefit from the findings made by SLE researchers in the context of their own research questions.

In what follows, both types of impact are discussed. With regard to the first of them, I point to the role of SLE in attracting the attention of linguists to sign languages (Section 2), gestures (Section 3), the problem of modality in communication (Section 4), or various interfaces between language and the environment (Section 7). On the other hand, I draw attention to those findings made by SLE researchers that have transformed or have the potential to transform the way linguists think about language and its study. The most important of these findings have come out of the experimental research on bootstrapping communication systems (Section 5) and the evolution of communicative structure (Section 6). The discussion opens and ends with the most general problem of the definition of language and how this definition reflects on the way language should be studied (Sections 1, 8 and 9).

\section{Rethinking design features of language}

Hockett's model of design features was for many linguists of the second part of the 20th century the most obvious reference point for looking at language from a biologically orientated, comparative perspective. His definition of language, extended in successive publications (Hockett 1958, 1959, 1960a, 1960b/1977, 1966; Hockett and Altmann 1968), is focused on the medium and structure of the communicative signal (Wacewicz and Żywiczyński 2015). In the bestknown typology consisting of 13 design features (Hockett 1960a), as many as 5 - Vocal-Auditory Channel, Broadcast Transmission and Directional Reception, Rapid Fading, Interchangeability and Total Feedback - are related (or at least are explained as related by Hockett as relating) to speech production and reception. The more systemic design features are discussed as properties of linguistic signs and treated in strictly behavioural terms. For example, semanticity is ex- 
plained as a communicative behaviour tied in a fixed way to elements of the environment; hence, Hockett thinks gibbon food calls or a rate or direction of bee dance are characterised by semanticity.

The inception of SLE led to a thorough-reassessment of the Hockettian way of thinking about language. In fact, the adoption of an evolutionary perspective demanded a Gestalt reversal of the account focused on means and code into an internalist conception of language. Scenarios of language evolution require the specification of preadaptations, or necessary conditions, for the emergence of language. Then, by setting these conditions against the baseline of the Last Common Ancestor we shared with non-human apes (LCA), SLE researchers can build scenarios of how and in what order they were achieved and in the way trace the evolutionary trajectory of language emergence (Żywiczyński and Wacewicz 2015). The most important of these prerequisites (or stepping stones towards language) are social, cognitive and anatomical in nature - as such they are not be directly visible in linguistic communication but nevertheless account of the uniqueness of language. The candidates for these "deep design features" of language under special consideration by SLE research are: cooperation with non-relatives, shared intentionality, metarepresentation and Theory of Mind, mimesis and intentional imitation, enhanced memory and executive function, symbolic representation, openendedness, and recursion (Deacon 1997, 2011b; Donald 1991, 1999; Hurford 2003; Tomasello 2008), all of which are better understood as cognitive skills rather than features of language in the E-sense (cf. Wacewicz and Żywiczyński 2015).

These evolutionarily motivated insights led to a redefining the ontology of language as a communicative system that is modality-independent (Ferretti et al. 2018 but see Section 4 below). Probably, the best-known attempt at such a redefinition is encapsulated in Chomsky and colleagues' concept of the Language Faculty (FL) with its aspect FL in the broad sense (FLB) and the - strictly linguistic - narrow sense (FLN) (Hauser et al. 2002). But interestingly, the same theoretical motivation lies behind conceptions of language that are otherwise very distant from Chomsky's position, such as Tomasello's understanding of language as a suite of socio-cognitive characteristics based on cooperativeness (2008) or Donald's mimetic conception of language and human culture (1991, 2001). Similarly, with regard to the comparative context, SLE makes us look not so much at the outward similarity between speech and, for example, vocal behaviours of non-human primates, such as food or alarm calls, but for the correlates of the uniquely linguistic characteristics. For example, the fact that linguistic communication is intentional, contextually flexible and directed at a spe- 
cific recipient makes it much more similar to the way apes use gesture than vocalisation (see below). In fact, nowadays there is a near consensus in SLE that there is more continuity between language and ape cognitive capacities than ape vocal communication.

Hockett's system of design features may still be a useful tool for describing selected properties of language and their outward similarity to selected properties of non-human communication systems. But it is radically unfit to capture the essential prerequisites for language, and SLE research has been instrumental in exposing this limitation, or in fact the limitation of any approach to the description of language that emphasises communicative means at the expense of content and code at the expense at the cognitive abilities of language users.

\section{Sign linguistics}

Sign linguistics now forms a distinct area of linguistics (Kendon 2012) and is independent of SLE, but it was the context of language origins that provided a strong impulse for its development at the break of the millennia. The founders of this line of research ${ }^{1}$ - Stokoe, Wilcox or Armstrong (Stokoe 1960, 2001; Armstrong et al. 1995; Armstrong and Wilcox 2007; cf. Emmorey 2002) - were intent on showing that sign languages have the same communicative potential and structural characteristics as modern spoken languages and, in doing so, appealed to the modality-independent view of language (see above). Interestingly, at the same time they pressed the point that the evolution of language probably started off with a gestural system because gestures are robustly iconic when compared to vocalisation and as such are better at bootstrapping a communication system (e.g. Stokoe 1960; Emmorey 2002). As we shall see (Section 5), the intuition about the bootstrapping potential of gestures was later confirmed by experimental research. They also argued that the spatial nature of gestures could account for the emergence of basic semantic roles and grammatical categories: since a gesture represents a complex situation (e.g. the action of pushing), it can conceptually be dissected into the agent (the pusher), the patient (the pushed) and the action itself (pushing); on a syntactic plane, the hand itself can be taken

\footnotetext{
${ }^{1}$ A regimented study of sign language was initiated in the 18th by teachers working with the deaf, for example, Roch-Ambroise Cucurron Sicard, the second director Paris's National Institute of the Deaf (Institution Nationale des Sourds-Muets ) in the custody of its director (see Żywiczyński 2018: 86-90). But these early studies were focused on pedagogical and rehabilitative problems, and not linguistic ones.
} 
to represent the prototypical noun, and the action performed by the hand, as the prototypical verb (Armstrong and Wilcox 2007).

A crucial dimension of the relation between sign linguistics and SLE is data provision: sign language studies constitute one of the most important sources of linguistic data for the research on language evolution. From the evolutionary perspective, the most attractive type of data are afforded by the study of emerging sign languages (Meir et al. 2010b). To set this problem in a wider perspective, it should be noted that SLE researchers use different types of linguistic data. Historical linguistic data are sometimes used with a view to capturing the dynamics of language change, ${ }^{2}$ for example, the theory of grammaticalisation has been drawn on to demonstrate how a lexical system could have acquired grammatical elements (e.g. Heine and Kuteva 2007). However, the evidence provided by the study of emerging sign languages, unlike historical linguistic data, uncovers processes of language emergence and change as they are happening, not through reconstruction. Similarly, research on creolisation is sometimes appealed to in SLE to speculate about language emergence. The obvious limitation of this line of argumentation is that creoles are based on existent language, while emerging sign languages provide a direct, in vivo insight into how fully fledged languages are born from non-linguistic forms of communication (see Bickerton 1990 for discussion). $\mathrm{R}$ esearch on emerging sign languages has shown how a system of idiosyncratic home signs - gestures typically produced by children to communicate with their parents (Goldin-Meadow and Mylander 1998) - changes first into an iconically motivated lexicon shared by a community of signers and in subsequent cohorts of signers, into a fully expressive and grammatically sophisticated language (Senghas et al. 2001; Senghas et al. 2004).

Probably, the best known example of such a process, often discussed in language evolution literature, is the emergence of the Nicaraguan Sign Language (NSL), which began with a cohort of deaf children brought together to a newly established institution for the deaf in Managua in the 1970s (Kegl et al. 1999). With the ensuing cohorts coming to the school, the iconicity of the original NSL has significantly eroded - signs became more economical and their meaning less transparent (Morford and Kegl 2000). These developments were accompanied by the emergence of syntax - the stabilisation of word order and the devel-

\footnotetext{
${ }^{2}$ This area of SLE is sometimes referred as glossogeny, and its specific research agenda is explaining how cultural-evolutionary processes bring about language change (see Żywiczyński and Wacewicz 2015: 130-132).
} 
opment of spatial grammar, which in sign languages is commonly used to indicate tense, mood, modality, shared reference or thematic structure (Senghas et al. 2001).

The growing bulk of research on emerging sign languages confirms the findings made by NSL researchers. For SLE, the key finding is that a linguistic system can de novo arise in the motor-visual channel (Meir et al. 2010a). Next, emerging sign languages that have been studied traverse a similar developmental trajectory. Their original lexicon is robustly iconic; it consists of pantomimic signs that involve high-span expressive movements (i.e. movements are broad and rich in detail, Beattie 2010) performed with the whole body, rather than just with the hands (Stamp and Sandler 2016; Lepic et al. 2016). Ensuing generations of signers produce more schematic, lower-span gestures (i.e. movements are constricted, see above), which instantiate less pantomimic communicative strategies - most importantly, character-viewpoint gestures (i.e. such that the gesturer's body parts pantomimically represent the same body parts; e.g. the pantomime of hammering a nail) are supplanted by object-viewpoint gestures (such that the gesture's body parts, typically the hands, represent something else than these body parts; e.g. two fists coming together representing a car crash; McNeill 1992; cf. Ortega and Özyürek 2019). On the syntactic ground, a stable word develops, often different from the one found in a language spoken by the same ethnic community. For example, Al-Sayyid Bedouin Sign Language used in Northern Israel by a Bedouin community with a high incidence of congenital deafness (Scott et al. 1995), shows a consistently SOV-word order, although the two languages spoken in the community - Hebrew and Arabic - as well as, puzzlingly, the Israeli Sign Language have different word orders (Sandler et al. 2005).

Without denying the self-identity of sign linguistics, its strong and continued focus on questions of language origin has substantially contributed to the development of this area of knowledge about language. Nowadays, sign languages are acknowledged as fully fledged languages by linguistic typologies; they are for example included in databases of the world's languages, such as Ethnologue (http://www.ethnologue.com) or World Atlas of Linguistic Structures (http://www.wals.info). And to an important extent, this situation has been facilitated by the evolutionarily motivated research agenda formulated by the founders of sign linguistics. SLE's influence is strongest in the study of emerging sign language, which have been brought to the attention of the linguistic audience by SLE researchers, and are now used as a reference point for the study of spoken languages (e.g. Pyers et al. 2010). 


\section{Protolanguage, Gestural Primacy Hypotheses and gesture studies}

Two methodological points are in order. First of all, we should address the problem of using contemporary linguistic processes, e.g. those found in emerging sign language, to reflect on the evolution of language. SLE researchers justify the use of such evidence by appealing to the Uniformitarian Principle (UP), which is one of the fundamental assumptions of the evolutionary science (for discussion see Newmeyer 2002). The UP, first formulated within geology by Charles Lyell (Principles of Geology, 1830), states that the same developmental processes that we see today operated in the past, including a distant, evolutionary past. In SLE, the UP validates the use of contemporary linguistic data, or as we shall see - experimental data with modern humans - to construct arguments about language's evolutionary past. This methodological stance explains why areas concerned with language development and change are of particular interest to SLE.

Another assumption of evolutionary science accepted by the majority of SLE researchers is that the emergence of a complex adaptive feature, in this case language, must have been a gradual process (see Pinker and Bloom 2012; for additional discussion, Żywiczyński and Wacewicz 2015: 118-119). ${ }^{3}$ The logic of gradualism dictates that the appearance of fully fledged language must have been preceded by a more primitive, quasi-linguistic system that has some but not all characteristics of modern language. This idea is encapsulated in the notion of protolanguage, which in $\mathrm{SLE}^{4}$ refers to a system of communication intermediary between the communication and cognition of non-human apes and fully fledged language (Scott-Phillips 2010; Żywiczyński et al. 2017). Home signs, the starting point for sign languages (see Section 3 above), creoles or a lexicon before the onset of grammaticalisation represent proxies for understanding what protolanguage may have looked like (see Section 3 above).

\footnotetext{
${ }^{3}$ There is a minority but influential view associated with Chomsky's idea of language emergence that can be best explained as a saltationist scenario (Chomsky 2010; Berwick and Chomsky 2016). Saltationism (from Latin saltus 'leap') assumes that evolutionary change is rapid and proceeds in discontinuous jumps, whereby a complex phenotypic trait is able to appear in the course of one or several generations.

${ }^{4}$ Protolanguage in the phylogenetic sense must be distinguished from the use of the term in historical linguistics, where it designates a hypothetical, reconstructed ancestor language of a particular language family (Żywiczyński and Wacewicz 2015: 184-185).
} 
A lot of SLE's debates revolve around the nature of hypothesised protolanguage, and they address this problem by asking various questions: What was its structure - was it combinatorial (e.g. Bickerton 1990; Jackendoff 2002) or holistic (e.g. Arbib 2012; Wray 1998; Mithen, 2005)?; What was its primary function? - was it communication (e.g. Wray 1998; Mithen 2005; Fitch, 2010) or representation of ideas (e.g. Bickerton 1990)?; or What was its modality? - was it gesture (Corballis 2003; Armstrong and Wilcox 2007), voice (e.g. Dunbar 1996; McNeillage 2008; Fitch 2010) or perhaps the combination of the two (e.g. Arbib 2012; Kendon 2011; McNeill 2012; Sandler 2013; Zlatev et al. 2017)? (for review of protolanguage debates see Fitch 2010 and Żywiczyński et al. 2017). Given the logic of gradualism inherent in the notion of protolanguage, it must have been within the reach of non-human apes, and hence - it is assumed - within the reach of the Last Common Ancestor of humans and non-human apes. $^{5}$

With regard to the problem of the modality of protolanguage, this mode of argumentation explains the popularity of gestural protolanguage hypotheses, often referred to Gesture Primacy Hypotheses (GPH; Hewes 1973, 1996; for a review see Orzechowski et al. 2016). There is a qualitative difference in the way extant non-human apes use gesture and vocalisation - gestures are used in a more language-like way than vocalisation, which involves intentionality, flexibility and ontogenetic plasticity ${ }^{6}$. The existence of this difference is also confirmed by attempts to teach enculturated apes some form of language, where the failed attempts to teach them vocal language (Furness 1916; Kellogg and Kel$\operatorname{logg} 1933$; Hayes and Hayes 1952) sharply contrast with the successful attempts to do so using the visual modality (e.g. Premack and Premack 1974; SavageRumbaugh et al. 1978, 1980), including sign language (Gardner and Gardner 1969, 1971; Patterson and Matevia 2001). There are important differences between the way gestures are used by humans and non-human apes, particularly free ranging apes. Importantly, the latter are virtually confined to gestures re-

\footnotetext{
${ }^{5}$ Usually referring to the Last Human Ancestor with representatives of the Pan genus - the common chimpanzee and the bonobo $\left(\mathrm{LCA}_{c}\right)$, who probably lived around 7-6 million years ago (Lewin and Foley 2004).

${ }^{6}$ This is the standard view of ape communication found in e.g. the works by Hewes $(1976,1977)$ or Corballis (2002); newer ethological research has demonstrated that the difference between gestural and vocal communication of apes may not be sharp as it was previously assumed; and the latter is characterised, at least to an extent, by functional reference, audience effects or tactical deception (for review see Slocombe 2011). These findings do not however question a qualitative difference between the two modes of ape communication (see e.g. Frölich et al. 2019).
} 
questing actions from their conspecifics, and whose form affords the performance of these requests; e.g. raising an arm as a gesture inviting another ape to engage in a grooming bout (e.g. Pika and Liebal 2006; for review see Fröhlich et al. 2019). The proponents of GPH use this evidence to argue that the idea of gestural protolanguage meets the requirements of an evolutionarily realistic, gradualistic scenario of language origin (e.g. Coraballis 2002; Arbib 2012). On the one hand, they are able to show evolutionary continuity with the gestural communication of humans and non-human apes (and hence the stipulated LCA); on the other, they are able to show that gestural protolanguage would have represented an advance over the gestural communication of non-human apes, which consisted into its acquisition of sign symbolic function (e.g. Donald 1991; Arbib 2012).

GPH have a long history in the Occidental intellectual tradition. Their popularity reached the peak in the Enlightenment, the golden age of glottogonic speculation, when they were popularised by the writings of Mandeville, Condillac, Rousseau and members of the influential Parisian Ideologue millieu (for details see Żywiczyński 2018: 100-122). The beginnings of SLE in the second part of the 20th century saw a revival of interest in gestural scenarios. The key role in this process was played by the anthropologist Gordon W. Hewes, who combined an encyclopaedic knowledge of historical views on language origins with modern, comparative outlook on the problem $(1973,1976,1977,1996)$. His seminal papers synthesise arguments for the gestural origin of language some of them are still an integral part of modern GPH (e.g. the focus on gestural communication of apes or the communicative potential of modern humans'gestures); others have been contested or ignored by later research (e.g. Hewes believed that the volar depigmentation is an adaptation for gestural communication - a biological vestige of gestural protolanguage; 1983). Since Hewes, GPH have enjoyed a growing popularity among SLE researchers, with some of the best-known, contemporary hypotheses on language origin subscribing to the gestural view; e.g. Arbib's Mirror Neuron Hypothesis (2005, 2012), Tomasello's socio-cognitive niche hypothesis (2008) or scenarios appealing to the mimesis theory (Donald 1991; Zlatev et al. 2017; Gärdenfors 2017).

Similarly to the development of sign linguistics, an evolutionarily motivated interest in gesture provided an impetus for the inception of gesture studies as an independent field. In contrast to anthropologically minded, early research on gestures (e.g. authored by Efron 1941; or Hall 1959, 1966), works produced by the founders of modern gesture studies - Kendon (1967, 1991, 2004), Ekman \& Friesen (1969) or McNeill $(1992,2005)$ - stress the role gestures played in the 
evolution of language, which leads them to uncover systematic relations between gesture and speech. Particularly, Kendon and McNeill are emphatic about an integration of gesture and speech into one cognitive-communicative system. For McNeill, these two modes of communication are co-expressive, with speech and gesture responsible for the transmission of different aspects of the message - the former, propositional information; the latter, imagistic content (1992). Speech and gesture are also co-temporal: the stroke of a gesture (i.e. the most pronounced phase of a gesture, preceded by preparation and followed by retraction; McNeill 1992) coincides with the semantically prominent element of an utterance, in this way externalising a Growth Point - the basic unit of thinking according to Mc Neill (1992). The idea of the Growth Point is also crucial to his conception of language emergence, the key moment of which was the integration between gestural and vocal communication, both at the level of cognition and expression (2012).

Kendon's model of Speech-Kinesic Ensemble is less categorical about a functional division between speech and gesture (2014). He argues that language emerged from practical skills related to hand-mouth coordination. Kendon draws attention to the fact, profusely illustrated by his own research, that many gestures "appear derivative of object handling actions", which - in his opinioncorroborates the hypothesis about "the original praxic nature of language" (2017). The conjoint evolution of vocalisation and gesture as expressive systems led to the situation where "words and gestures labor together to produce virtual objects that serve as conceptual expressions" (2014). Importantly, this way of meaning making, or "languaging" (Kendon 2004), depends on a dynamic interaction between the two systems whereby they support but also adapt to each other (Kendon 2017).

Kendon's view on the relationship between speech and gestures have been used by Kita, who elaborated probably the most influential psycholinguistic model that integrates these two semiotic resources (Kita and Özyürek 2003). Kita argues that gesture and speech production depend on separate, though closely related, communication pathways - the Message Generator for speech and the Action Generator for gesture. The former is focused on propositional information in the producer's working memory; the latter, on spatio-motoric information. However, this division of labour is not strict, and in Kita's view, the semi-independent nature of speech and gesture production explains bidirectional links between them. Rich empirical material gathered by Kita and his collaborators illustrates how a message expressed by speech impacts a gesturally expressed message, and the other way round - how a gestural message 
impacts a spoken message. ${ }^{7}$ Linguistic packaging of information is the effect of the interaction between speech and gesture (Kita et al. 2017).

The study of gestures, deeply seated in the context of language evolution, has opened a new vista on the understanding of language. Language is increasingly viewed not as a static system of relations and contrasts (ultimately derived from de Saussure, 1916), but a statu nascendi reality that emerges in face-toface interaction ("the core ecological niche for language", Torreira et al. 2015) from the integrated use of the vocal and gestural modalities (see Vigliocco and colleagues" programmatic text "Language as a multimodal phenomenon", Vigliocco et al. 2014). Apart from psycholinguistics, the area of languages studies that has greatly been affected by this new perspective is Conversation Analysis (Sacks and Schegloff 1973; Schegloff 1996), where the study of such phenomena as turn-taking (Sacks et al. 1974) or preference organisation (Pomerantz 1984) now often takes into consideration interactants' visually transmitted information, including gaze, facial expressions and gestures (for a review, see Żywiczyński et al. 2017). This research feeds back to SLE and contributes to a growing recognition of positions that link language emergence to the evolution of human-specific types of interaction, such as Levinson's (2006) interaction engine hypothesis, which views human linguistic communication as based on a suite of socio-interactive capabilities.

\section{Bootstrapping communication and iconicity}

Another line of research important to SLE that addresses the problem of vocal and gestural communication is focused on the conditions necessary for bootstrapping a communication system. In SLE, bootstrapping studies are experimental and usually employ the methodology of experimental semiotics, which studies how humans develop novel communication systems in the absence of a shared code (Galantucci 2009, 2017; Galantucci and Roberts 2012). The results of experimental-semiotic research are often used as evidence supporting in-

\footnotetext{
${ }^{7}$ For example, they found that speakers of languages, in which manner and path of movement are expressed by one lexical item, tend to produce one gesture that jointly captures the two aspects of movement, while speakers of languages, in which manner and path are expressed by two lexical items, tend to produce separate gestures for manner and direction. Their studies also showed that when participants are asked to produce either one or two gestures for manner and path of movement, they later tend to express the two aspects of meaning with, respectively, one clause and two clauses (for review of these studies see Kita et al. 2017).
} 
sights into the origin of language provided by linguistic data, such as those that come from the research on emerging sign languages. The key problem that bootstrapping studies highlight is what, following Harnard (1990), has come to be known in modern philosophy of language as "the symbol-grounding question" - "How can meanings arise bottom-up - from meaningless tokens" (cf. Fay et al. 2014).

In the beginning, a lot of such experimental research was conducted with artificial agents. One of the best-known studies in this tradition was the "talking heads experiment" by Steels and colleagues (2015). Using a version of the "guessing game" design", they programmed two computer agents to communicate a range of meanings to each other by means of arbitrary symbols. If the hearer agent correctly guessed the speaker agent's intended meaning, a success signal was sent. If it failed to do so, a fail signal was sent. On the basis of this feedback, agents' lexicons were updated using a reinforcement-learning algorithm. Over many thousands of pair-wise interactions, arbitrary signal-meaning pairings became conventionalised in a population of agents.

Research into bootstrapping communication with the use of artificial agents has been expanding (e.g. nowadays a lot of such studies involve embodied robots; for an overview, see Steels et al. 2012), but in recent years the interest of SLE researchers has shifted to human-based experiments. Unlike Steels's talking robots, human participants have a limited memory and usually do not receive explicit performance feedback in communicative situations; hence, it is argued that human-based experiments can better inform our knowledge of the evolution of meaning (cf. Galantucci and Roberts 2012). Experimental-semiotic research (see above) showed that human participants engaged in interaction are able to quickly elaborate communicative conventions from scratch (Galantucci

\footnotetext{
${ }^{8}$ This is how Harnard (1990: 335) describes the symbol-grounding problem: "[T]he symbol "grounding problem": How can the semantic interpretation of a formal symbol system be made intrinsic to the system, rather than just parasitic on the meanings in our heads? How can the meanings of the meaningless symbol tokens, manipulated solely on the basis of their (arbitrary) shapes, be grounded in anything but other meaningless symbols? The problem is analogous to trying to learn Chinese from a Chinese/Chinese dictionary alone."

${ }^{9}$ Guessing game: "This is a game played among two agents, in which the speaker chooses a topic from the white board, conceptualises it, and communicates it verbally to the hearer. The hearer then has to guess which topic was chosen. If he fails, speaker and hearer repair their conceptual layers and lexical layers. The process is repeated, and multiple agents act in turn as speakers and hearers, while the elements on the white board are constantly changing. The guessing game is assumed to model the real world situation, in which children learn a language through communicative interaction with other language speakers (e.g. that elephant?).” (Steels 2006)
} 
2017). It also became clear that what allows participants to get a communicative system off the ground is the use of motivated (for the most part, iconic) signs (e.g. Fay et al. 2013; Zlatev et al. 2017). Most interestingly, repeated and interactive use of motivated signs leads to their simplification and the emergence of more arbitrary ones. For example, in a famous study Garrod and colleagues (2007) had pairs of participants communicate graphically a series of easily confusable items (e.g. a microwave, television or computer monitor), and either allowed them to interact with each other or not. With even a very minimal level of graphical interaction (e.g. the use of a tick to indicate comprehension), partners' drawings converged and developed from iconic to arbitrary signs - this tendency was more pronounced when players alternated roles in drawing and guessing. In the non-interactive condition, drawings remained iconic and instead of becoming simpler they gained in complexity. The authors argued that interaction promotes a shift in the locus of information from the sign to the users' memory, allowing the signs to become simpler (cf. Clark 1995). The results obtained by Garrod and colleagues (2007) and similar studies (e.g. Tamariz et al. 2017) provided evidence that an initial stage of the bootstrapping process heavily depends on motivated signs, and that a repeated, interactive use of motivated signs increases their arbitrariness, usually by the erosion of iconicity.

From the perspective of language evolution, particularly in the context of protolanguage debates (see Section 4 above), one of the most interesting questions related to bootstrapping research was which modality is best at bootstrapping a communication system. Predictably ${ }^{10}$, experimental-semiotic research has confirmed that the gestural modality is significantly better at accomplishing this task than the vocal one (Fay et al. 2013; Fay et al. 2014). A less intuitive outcome of these studies, particularly in the context of multimodal conceptions of language (see Section 4 above), is that combing gestural and vocal signs does not give participants an edge over unimodal, gestural signs. For example, in the classic studies of this problem by Faye and his collaborates (Fay et al. 2013; see also Fay et al. 2014), participants had to communicate to each other emotions (e.g. tiredness, pain, anger), actions (e.g. fleeing, sleeping, fighting) and objects (e.g. rock, fruit, predator) by means of improvised gesture, non-linguistic vocalisation or both. The results showed that the gestural and the gestural-vocal conditions were significantly better than the vocal condition, but there was no significant difference between these two. This second result was replicated by

${ }^{10}$ Refer back to the research on the role of iconicity and its loss in emerging sign languages (Section 3). 
Zlatev and colleagues (2017), who found no significant difference in guessability of pantomimed transitive events that were either accompanied or unaccompanied by non-linguistic vocalisations.

These results corroborate the evidence gathered from research on emerging sign languages, and on a standard evolutionary interpretation they are seen as supporting gestural scenarios. Many influential proponents of GPH, e.g. Arbib (2012), Zlatev (2008) or Gärdenfors (2017), agree on the following course of evolutionary events: the original modality of protolanguage was gesture, whose iconic potential allowed for bootstrapping a basic communication system. With an incremental crowding of the semantic space, the use of iconic signs became cumbersome, which pushed protolanguage into the vocal modality, better suited for arbitrary signs (Manoghan et al. 2014). A growing appreciation of this scenario has met with growing criticism. Supporters of vocal scenarios underline the scale of the human adaptations for speech, both at the level of anatomy and neural implementation and the problem of modality transition of hypothesised gestural language into the vocal modality (McNeillage 2008; Fitch 2010; for discussion of the transition problem see Orzechowski et al. 2016). There is also a line of criticism that focuses on iconicity as the assumed original mechanism responsible for bootstrapping the original protolanguage. Here, the authors such as Irvine (2016) and Abramova (2018) summon data showing that iconicity is cognitively difficult; for example, it is beyond the reach of non-human apes and it emerges late in the development of children.

Evolutionarily motivated debates about iconicity have contributed to rejuvenating interest in the role of iconicity in modern languages. Unlike early cognitive linguists' attitude to the subject (most importantly, shaped by the theory of conceptual metaphor; Lakoff and Johnson 1980; Lakoff 1987; Lakoff and Turner 1989), the recent approach is characterised by a strong empirical orientation (for discussion see Fitch 2017), including experimental research. There is an interesting line of experimental-semiotic research that investigates the iconic potential of vocalisation. Using the guessing game paradigm (see above) or the foreign language paradigm (Skirgård and Roberts 2018), a number of researchers affiliated with SLE (Perlman 2017; Clark 2016; Imai and Kita 2014; Lockwood and Dingemanse 2015; Perlman and Cain 2014; with the programmatic paper by Perlman et al. 2015) have managed to show a non-negligible iconic capacity of vocalisations, and argued that the vocal modality might have played a role in bootstrapping the semantics of protolanguage (Perlman 2017). Next, the creation of large language databases (see Section 3 above) facilitated a BIGDATA approach to the study of various linguistic facts (see Section 8 below), 
including iconicity in spoken languages. In a pioneering study, Blasi and colleagues (2016) showed the results of a study based on 6,452 languages. The authors constructed a 40-word sample derived from the Swadesh list (Swadesh 1971) and used the Automated Similarity Judgment Program to assess the phonetic similarity between the words from the sample across the selected languages. Controlling for historical similarity between these languages and their aerial dispersal, they managed to demonstrate that a significant proportion of words in the word-sample are biased to carry or to avoid specific sound segments. The result led Blasi and collaborates to speculate that lexicons of modern spoken languages exhibit a noticeable component of non-arbitrariness, the existence of which is best explained by iconicity. ${ }^{11}$ The results obtained by Blasi and by researchers investigating the iconic potential of non-linguistic vocalisation go against the old Saussurean dogma about the arbitrariness of the linguistic sign. ${ }^{12}$ They also question the assumption characteristic of gestural and multimodal scenarios of language origin about a qualitative difference in the iconicity of vocal and gestural signs. Although this line of research occupies the periphery of SLE and even more so of modern linguistics, in these two important respects it is capable of modifying our deeply seated ideas about the way we understand linguistic meaning and its evolutionary underpinnings (see Perlman 2017 for a programmatic statement).

\section{An experimental approach to the evolution of linguistic struc- ture}

Another key area of SLE experimental research is focused on the evolution of morphological and syntactic structure. The research on sign languages inspired researchers to ask the question about the basic word order (Comrie 1981; Boruta and Placiński 2017) typical of motor-visual communication. Although there is as much variety in this regard in signed as in spoken language (Napoli and Sutton-Spence 2014), the overwhelming majority of sign languages uses the S-O-V order irrespective of the basic word order used in languages spoken by communities in which signers are immersed (see Section 3 above). Furthermore, the research on home signs (see Section 3 above) demonstrates that their combina-

\footnotetext{
${ }^{11}$ They also mention other processes that might account for this result, such as communicative pressures (Blasi et al. 2016).

${ }^{12}$ But see Jespersen (1923) or Ohala (1983).
} 
tions tend to be the same word order, again irrespective of the spoken environment in which a home-signing child is being brought up (Goldin-Meadow and Mylander 1998). Experimental research has, partially, confirmed that the S-V-O order is characteristic of improvised gestural communication. In a landmark study (2008), Goldin-Meadow and her collaborators showed that both speakers of SOV languages (Turkish) and SVO languages (English, Chinese and Spanish) - in an experimental setting - resorted to the SOV sequence when gesturally communicating simple transitive events (e.g. woman-twists-knob). Later research showed that the SVO order consistently manifests itself only when S and $\mathrm{O}$ are irreversible, i.e. when the semantic constraints makes it possible for the entity designated by $\mathrm{S}$ and the entity designated by $\mathrm{O}$ to change their syntactic roles (e.g. BOY vs. BALL; Meir et al. 2010b, Gibson et al. 2013, Hall et al. 2013). In irreversible situations, i.e. such where $S$ and $O$ designate entities that are both plausible Agents (BOY vs. GIRL), participants tend to separate $\mathrm{S}$ and O by the V component (e.g. BOY PUSH GRIL; Hall et a. 2013). Based on the results of these studies, it has been hypothesised that the S-O-V order for irreversible situations and the SVO for irreversible ones are cognitively and evolutionarily primary (Żywiczyński et al. 2018). The proponents of a competing hypothesis set these findings against the data on word order typology in spoken languages, where the SVO order dominates and argue the configurations of word-orders in gestural communication (and to an extent in sign languages) are modality-specific and result from its robust iconicity (Hall et al. 2013).

The area of SLE that has probably exerted the biggest impact on our understanding of language is the research conducted in the iterated learning paradigm. SLE iterated learning studies are aimed at explaining the way cultural transmission influences linguistic structure. The more specific question asked by this tradition is how cultural transmission, i.e. passing the stimulus set through subsequent generations of learners, transforms randomly assigned forms and meanings into a systematically ${ }^{13}$ organised lexicon (for a review see Kirby 2017). The basic logistics of iterated learning studies are derived from the Bayesian learning model, in which initial probabilities of hypotheses about a set of data are upgraded after being exposed to this set (Stanford Encyclopedia of Philosophy, 2019). In modelling research, simulated agents learn to associate signals (usually strings of characters from an alphabet) to meanings (e.g. numeric vectors, or structured representations of some external environment) by observing a

${ }^{13}$ Kirby (2017) defines systematicity in the following way: "[A] set of behaviours exhibits systematic structure to the extent that they are interdependent rather than independent of each other." 
sample of the signalling behaviour of other agents in the simulation. In Bayesian iterated learning, the second agent observes the signalling behaviour of the first agent, which leads to an upgrade of the model and this upgraded version is then shown as the signalling behaviour observed to the third agent, which again upgrades the model and this upgraded version is shown as the signalling behaviour to the fourth agent, and so on (for discussion see Lipowska 2016: 60-90).

The early modelling work by Hurford and his collaborators (Hurford 1989; Kirby and Hurford 2002; Smith et al. 2003) demonstrated that iterating a random set of signs in the manner described above leads to its systematisation, i.e. signs become increasingly interdependent and finally acquire compositionality, whereby the meaning of a signal is determined by the meanings of its constituent expressions and the rules used to combine them (Kirby 2000). There are two conditions that must be met for this to happen: agents must be equipped with a bias for learnability, which favours simple and predictable signals, and the processes of transmission must go through a bottleneck - a successive agent can only be exposed to part of the system learnt by a preceding agent (Smith et al. 2003). According to Hurford (e.g. 2012), these constraints realistically capture the dynamics of language transmission. As the modelling research shows, language can be learnt from a limited amount of linguistic data (i.e. with a bottleneck imposed on an iteration chain), but more importantly, the transgenerational transmission of language shapes it to become increasingly learnable by agents who are equipped with a simplicity bias. This is because changes introduced into the evolving language at each generation are able to persist only to the extent that they are easy to acquire by subsequent generations. The inevitable result is a cumulative increase in learnability of the transmitted system, which eventually leads to the emergence of compositional structures.

Hurford and Kirby (2001) transposed these findings onto the evolutionary plane and proposed the following model (see Figure 1): learning biases, and specifically a simplicity bias, are the effect of biological evolution and have evolved under selection pressures for more effective communication. At the ontogenetic level, biases allow learners to acquire language, without the necessity of learners being exposed to a complete language system. In effect of the process of acquisition by ensuing generations of learners, language adapts to biases and becomes more learnable by subsequent generations of users, and through a feedback loop, increasingly learnable language puts a selective pressure on subsequent generations of learners to evolve stronger biases to learn such language. In this way, the biological evolution of language users and the cultural evolution of language change are integrated into one evolutionary process. 


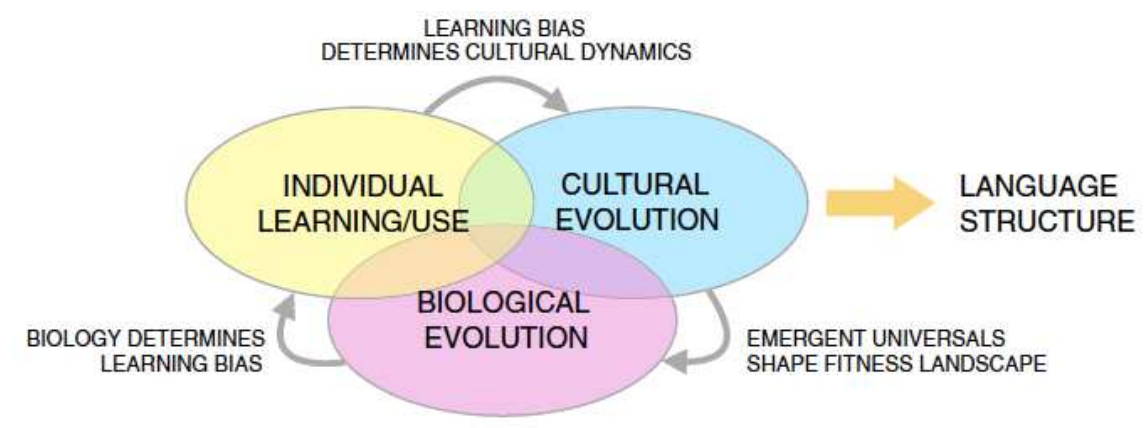

Figure 1. The Hurford-Kirby model of the co-evolution between learning biases and language structure (taken from Kirby 2017).

As was the case with the research on bootstrapping, iterated learning studies based on modelling were followed by similarly designed experiments with humans (cf. Lipowska 2016). The use of human participants was likewise motivated by a limited validity of the modelling research for the evolution of language - unlike artificial agents, human participants have stringent memory limits, and the logistics of experiments with humans does not allow experimenters to multiply the number of iterations as they find fit. The assumption underling this research was that human subjects have a strong, intrinsic simplicity bias, and hence, even within the span of a few generations of learners, an initial set of random signals was expected to become more learnable, primarily through the emergence of compositionality (Kirby 2017).

In one of the first experiments of this type, Kirby and collaborators (2008) had participants learn a miniature artificial language in which strings of syllables labelled coloured moving shapes (see Figure 2). There were three colours, three shapes and three movement types, leading to 27 possible combinations of these 3 dimensions of meaning. In the initial language, the strings were randomly assigned to the shapes. After being exposed to half of this language, ${ }^{14}$ participants were asked to label the full set of 27 items, i.e. they not only had to recall the strings they were trained on but also generalise what they had learnt to unseen strings. The language elicited from the first participant was used to train

\footnotetext{
${ }^{14}$ In this way the stimulus was bottlenecked; see above.
} 
the second participant in the experiment (with a different selection of items withheld from training). This process was repeated for 10 generations of learners in four separate chains, each of which began with a different initial language. The experimenters expected that at the end of iteration chains, the three dimensions of meaning - colour, shape and movement type - would be expressed by three distinct elements of the evolved signals. But, as Figure 2 exemplifies, the iterations resulted in degenerate languages that consisted of a small number of signals that underspecified the designates.

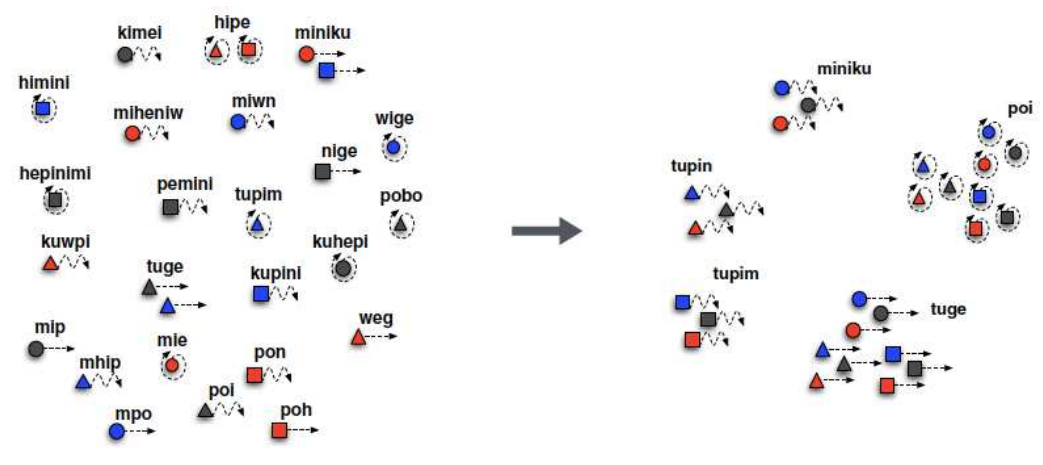

Figure 2. The initial and final language in one of the iteration chains in the research by Kirby et al. 2008 (taken from Kirby 2017).

Later studies confirmed that the experimental protocol described above does not facilitate the emergence of compositionally organised languages but, instead, triggers an evolutionary trajectory leading to an undersized set of underinformative and randomly organised signals. The way this result was interpreted focused on the role of memory in iteration tasks - as already mentioned, when compared to artificial agents, human participants have severe memory limits. Hence, the most learnable sets are those that consist of a minimal number of signals with the optimal set consisting of only one element, which in fact was the outcome of some iterated learning experiments (Kirby 2017). Since in the case of human subjects the pressure for learnability is not enough to evolve compositional signals, researchers sought new experimental designs that could better capture the evolution of structured communication. 
Kirby and his collaborators came to the conclusion that iterated learning experiments must put combined pressure for learnability and expressivity on participants. New designs were constructed to incorporate these two types of pressure. For example, in the study by Winters and colleagues (2015), an artificial language was not only transmitted between generations of learners, as is in the classic iterated learning design, but was also transmitted horizontally between learners form the same generation, who used the signals in a guessing game, changing the roles of Director and Matcher (see also Kirby et al. 2015). Figure 3 illustrates the emergence of partly compositional structure with protomorphemes signifying different shapes and colours.

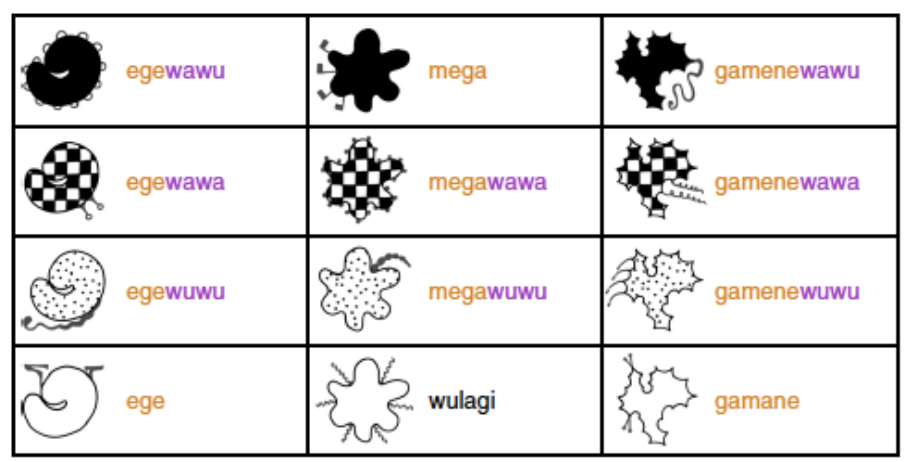

Figure 3. The formation of the quasi-morphological markers of shape and colour in Winters et al.'s study (2015; taken from Kirby 2017).

Other studies using the iterated-interactive design have confirmed that the combined pressure for learnability and expressivity leads from random sets of signals to structured systems of communication (e.g. Kirby 2015, for review see Kirby 2017). Currently, this line of research is not limited to investigating the evolution of compositional morphology, but covers a range of other subjects, including the evolution of syntax. In an interesting study, Motamedi and collaborators (2017) used the iterated-interactive design to study the emergence of strategies for indexing arguments as $\mathrm{S}$ and $\mathrm{O}$ in improvised gestural communication. The results show that iterations led to a stable indexing system, although participants in different chains elaborated distinct indexing strategies - some of them invented lexical labels, others made use of space and indexed the argu- 
ments either by body orientation or trajectory of hand movement. Interestingly, similar spatial strategies are common in sign languages (see e.g. Padden et al. 2010).

To put these results on a more general level, the iterated learning research illustrates the importance of cultural transmission, both vertical (or transgenerational) and horizontal, (i.e. between interacting individuals), for the development of structural characteristics of language, most importantly compositionality. In accordance with the Hurford-Kirby model (see Figure 1), there is a feedback loop between biological, individual and cultural evolution; however, the results of these experiments strongly suggest that once the biological evolution equipped hominins with biases, evolution of linguistic structure could solely have depended on the logistics of cultural evolution, without any major intervention of biological evolution (see also Deacon 2011a for the problem of selfdomestication; and Tomasello 1999 for the problem of cultural ratchet effect).

\section{Language and environment}

In very general terms, iterated language experiments with humans reflect on how language is shaped by social factors, which are operationalised as the vertical transfer of language between generations of learners and the horizontal transfer between learners of the same generation (Kirby 2017). This problem is of huge interest to language evolution because it brings into focus the scale of cultural-evolutionary processes involved in language emergence and language change (Hurford 1999, 2003). The problem is likewise important to the theory of language, where it addresses the Humboldtian sentiment about the impact of a group's social characteristics on the structure of a language used by this group (Humboldt 1836/1999). The construction of large linguistic corpora (see Section 8 below) has facilitated Big-Data studies into the interrelation between structural and socio-demographic characteristics of languages. One of the most thoughtprovoking of these is Lupyan and Dale's research about the relation between demographic characteristics and language morphology (2010). Lupyan and Dale correlated the exponents of inflectional morphology of a language and the size of its speakers' population in the sample of approximately 2000 languages. Controlling for the influence of geographical spread and degree of language contact, they showed that languages spoken by larger groups typically have vestigial declinational and conjugational systems and use lexical strategies, rather 
than inflectional morphology, to encode a variety of grammatical information, such as evidentiality, negation, aspect, and possession.

Lupyan and Dale link these results to the Linguistic Niche Hypothesis (LNH), formulated by Trudgill within sociolinguistics (2002) and later developed in the evolutionary context by Wray and Grace (2007). The hypothesis stipulates that languages adapt to social niches in which they are used, similarly to the way biological organisms adapt to the ecologies they inhabit (Wray and Grace 2007). The hypothesis introduces a key distinction into exoteric and esoteric niches and the resultant distinction into exoteric and esoteric languages. Exoteric niches contain languages used by heterogeneous groups, putting the pressure on these languages to become suited for communication between strangers and become more learnable by non-native, often adult, users (Lupyan and Dale 2010). English, Swahili and Hindi are often given examples of typical exoteric languages, in that they are likely to be used by individuals from different cultural backgrounds and to be learnt by non-native speakers (Wray and Grace 2007). Conversely, esoteric languages, exemplified by Tatar, Elfdalian and Algonquin (Wray and Grace 2007), are spoken by small, tightly knit populations, whose members have a strong sense of personal familiarity and shared cultural identity.

SLE's evolutionary agenda provides a context for studying ways in which not just social but environmental and biological factors impact languages. In one of such studies, Everett and colleagues (Everett et al. 2015) correlated the distribution of tonality across language families and came to the conclusion that it is, to an important degree, dependent on environmental factors. They found that tonal languages are absent in very cold or dry climates, and, appealing to laryngology, argued that such environments increase phonatory perturbations, such as jitter and shimmer, making the effective use of tonal distinction difficult. The sequencing of the human genome (The Human Genome Project, 1990-2003) opened up a new fascinating area of exploring linguistic characteristics in relation to the genetic make-up of its users. In a pioneering study, Dediu and Ladd (2007) linked the differences in the brain size genes ASPM and Microcephalin to the distribution of populations using tone languages. The results of such studies are difficult to interpret in a straightforward way, but they suggest that some cognitive, language-related biases are coded genetically and that these biases can affect the trajectory of language change (cf. Dediu 2008; Dediu et al. 2017). As already noted, SLE researchers take a rather broad perspective on how environment impacts language. The use of demographic, climatic or genetic clues to disentangle this problem certainly lies beyond the traditionally 
construed linguistic methodology. The innovative approach espoused by SLE researchers is in this way able to discover facts about the environmental determinants of languages that linguists themselves are not prompt to consider, but which have the potential of informing linguistic research, particularly in the area of typology.

\section{The nomothetic approach}

The methodology underlying the type of studies described above have influentially been termed as the nomothetic approach to the study of linguistic data. Roberts and Winters (2012), who coined the term, contrast the nomothetic approach with the idiographic approach. They take the latter to characterise the traditional methodology used in empirical linguistics, chiefly in typological and sociolinguistic studies. The idiographic approach is motivated by careful casestudies motivated expressly stated hypotheses (Roberts and Winters 2012). As an illustration, let's look at MacKeigan and Muth's (2006) study on the relation between colour terms and social variables. The peculiarity of Tzotzil, the Maya language studied by MacKeigan and Muth, is that it has hundreds of compounds for describing various dimensions of colour. MacKeigan and Muth (2006) put forward the hypothesis that the profusion of Tzotzil colour terms is motivated by the fact that the dominant industry of the Tzotzil people is the manufacture of traditional colourful textiles. Their extended sociolinguistic study verified this hypothesis by demonstrating that as weavers work in groups, they need fine-grained labels for requesting specific threads form their co-workers. MacKeigan and Muth were even able to track the spread of individual colour terms within the social network of weavers.

Their study captures the essential qualities of idiographic research - reliance on a hypothesis-driven case study, the results of which may but do not have to be generalisable to other linguistic contexts. In contrast, the nomothetic approach is not focused on empirical details but seeks law-like explanations of general phenomena based on the study of large sets of data. Importantly, nomothetic research is not hypothesis-driven; hence, its results are purely correlational and as such do not help identify mechanisms responsible for discovered correlations. Of course, it is possible to put forward a post-hoc hypothesis in attempt to identify such a mechanism, as was the case with Lupyan and Dale (2010) or Everett and colleagues (2015). The latter example is particularly illustrative of the power of the nomothetic approach to generate new hypotheses - 
the relation of tonality and air desiccation is far from obvious and probably would have gone unnoticed but for a large-scale, correlation study.

The easy access of large datasets, such as WALS or Ethnologue, and the availability of tools to analyse them makes the logistics of hypothesis-seeking research quick and easy, particularly when compared to the toilsome logistics of idiographic research. There are of course rather obvious drawbacks of the nomothetic approach. Apart from methodological concerns, nomothetic research is not sensitive to the quality of data and the way they are integrated into typological frameworks, but unreflectively relies on the work and decisions made by architects of databases. Paradoxically, the sheer size of databases used in nomothetic studies can also pose a threat to their integrity, as large datasets are likely to contain spurious correlations between variables that have no direct causal link. Roberts and Winters (2012) exemplify the correlational fallacy with a study showing that populations inhabiting areas where the acacia tree Acacia nilotica grows are significantly more likely to have tonal languages; however, even in the wildest stretch of imagination, it is difficult to posit a direct causal link between the incidence of Acacia nilotica and tonal languages. Despite these limitations, the nomothetic approach, if used wisely as a hypothesis-seeking device, can vastly contribute to our understanding of the ways language is implicated into social, biological and ecological contexts.

\section{Conclusion: Language is not autonomous}

The review of SLE's contributions to linguistics has included both areas whose impact has already been felt and those that have the potential to exert influence in the near future. The former include the study of sign languages, including emerging sign languages, gesture studies, and research on iconicity and the role of modality for the organisation of language. As shown here, linguists' growing appreciation of these fields is too a significant extent the result of the activity of SLE. Similarly, the research on the relation between social factors and language structure has infiltrated linguistics, and the discovery of deep design features of language. On the other hand, mainstream linguistics has not so far shown much interest in the research into the pressures that genes and ecologies put on languages. Also, it is yet to fully acknowledge the role of cultural evolutionary processes in shaping language or the utility of the nomothetic approach in generating linguistic hypotheses. 
As noted in the introduction, SLE's research agenda is much broader. Figure 5 adapted from the seminal paper by Christiansen and Kirby (2003) shows the most important fields that language evolution research relies on. Apart from possibilities of integrating all the lines of research related to these fields into linguistic research, the scope of SLE illustrates a more general point - language is not autonomous but part and parcel of a variety of evolutionary, biological and cognitive-behavioural mechanisms (cf. Botha 2000).

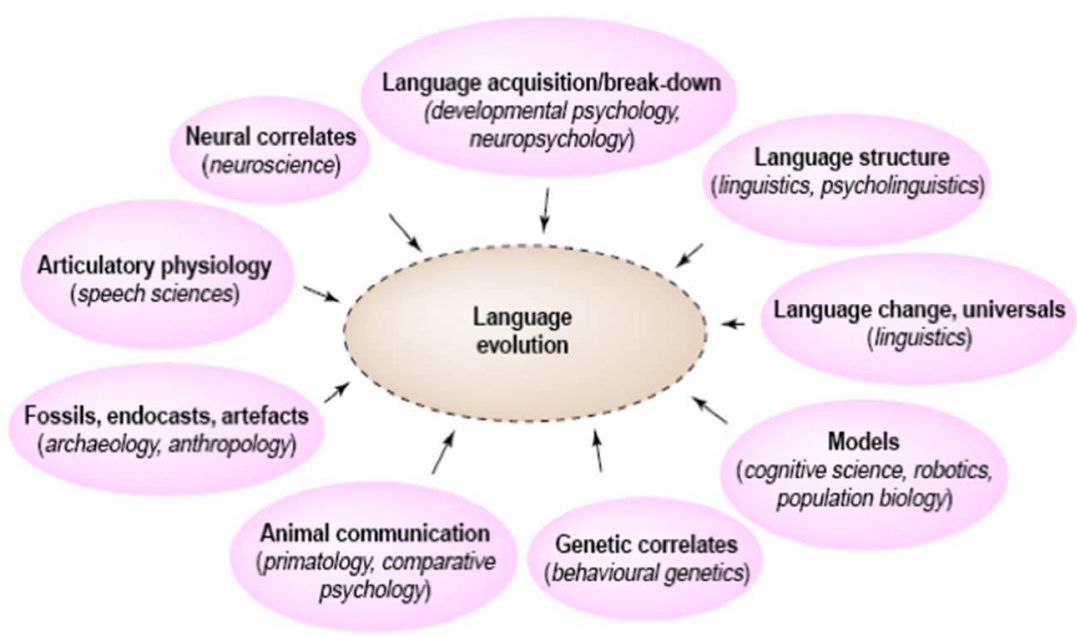

Figure 4. The areas of research contributing to SLE according to Christiansen and Kirby (2003).

This ontological statement leads to a methodological postulate that the study of language should be informed by evidence gathered by research on these mechanisms. Accordingly, similarly to SLE researchers, linguists should be on the lookout for such evidence and set against the predictions of linguistic theories, in the way that SLE researchers do that against the predictions of their scenarios of language emergence. Such an approach goes against the foundational myth of linguistics being an autonomous science (e.g. Humboldt 1836/1999; de Saussure 1916/1959), but it presents a chance of transforming linguistics into an empirically orientated, normal science in the Kuhnian sense (Kuhn 1962). 


\section{References}

Abramova, E. 2018. The role of pantomime in gestural language evolution, its cognitive bases and an alternative. Journal of Language Evolution 3(1). 26-40.

Arbib, M. 2005. From monkey-like action recognition to human language: An evolutionary framework for neurolinguistics. Behavioral and Brain Sciences 28. 105167.

Arbib, M. 2012. How the brain got language. Oxford: Oxford University Press.

Armstrong, D., W. Stokoe and S. Wilcox. 1995. Gesture and the nature of language. Cambridge: Cambridge University Press.

Armstrong, D. and S. Wilcox. 2007. The gestural origin of language. Oxford: Oxford University Press.

Bickerton, D. 1990. Language and species. Chicago: University of Chicago Press.

Blasi, D., S. Wichmann, H. Hammarström, P. Stadler and M. Christiansen. 2016. Sound-meaning association biases evidenced across thousands of languages. Proceedings of the National Academy of Sciences 113(39). 10818-10823.

Boruta, M. and M. Placiński. 2017. The syntax in pantomimic re-enactments of events among Polish participants. Culture and Education Journal 2(116) (Łysomice: Adam Marszałek). 106-118.

Botha, R. 2000. Discussing the evolution of the assorted beasts called language. Language and Communication 20(2). 149-160.

Chomsky, N. 2010. Some simple evo-devo theses: How true might they be for language? In R. Larson, V. Déprez and H. Yamakido (eds.), The evolution of human language. 54-62. Cambridge: Cambridge University Press.

Chomsky, N. 2016. What kind of creatures are we? New York: Columbia University Press.

Christiansen, M. and S. Kirby. 2003. Language evolution: Consensus and controversies. Trends in Cognitive Sciences 7(7). 300-307.

Clark, H. 1995. Using language. Cambridge: Cambridge University Press.

Clark, H. 2016. Depicting as a method of communication. Psychological Review 123(3). 324-347.

Comrie, B. 1981. Language universals and linguistic typology: Syntax and morphology. Chicago: University of Chicago Press.

Corballis, M. 2002. From hand to mouth: The origins of language. Princeton: Princeton University Press.

Corballis, M. 2003. From mouth to hand: Gesture, speech, and the evolution of righthandedness. Behavioral and Brain Sciences 26(2). 199-208.

Deacon, T. 1997. The symbolic species: The co-evolution of language and the brain. New York: W. W. Norton and Company.

Deacon, T. 2011 a. Incomplete nature: How mind emerged from matter. London: Norton \& Company.

Deacon, T. 2011b. The symbol concept. In K. R. Gibson and M. Tallerman (eds.), The Oxford handbook of language evolution. 393-405. Oxford: Oxford University Press. 
Dediu, D. and D. R. Ladd. 2007. Linguistic tone is related to the population frequency of the adaptive haplogroups of two brain size genes, ASPM and microcephalin. Proceedings of the National Academy of Sciences 104(26). 10944-10949.

Dediu, D. 2008. The role of genetic biases in shaping the correlations between languages and genes. Journal of Theoretical Biology 254(2). 400-407.

Dediu, D., R. Janssen R. and S. R. Moisik. 2017. Language is not isolated from its wider environment: Vocal tract influences on the evolution of speech and language. Language \& Communication 54. 9-20.

Donald, M. 1991. Origins of the modern mind: Three stages in the evolution of culture and cognition. Cambridge: Harvard University Press.

Donald, M. 2001. A mind so rare. The evolution of human consciousness. New York: Norton.

Dunbar, R. 1996. Grooming, gossip and the evolution of language. London: Faber \& Faber.

Efron, D. 1941. Gesture and environment. New York: King's Crown Press.

Ekman, P. and W. V. Friesen. 1969a. The repertoire of nonverbal behavior: Categories, origins, usage, and coding. Semiotica 1. 49-98.

Emmorey, K. 2002. Language, cognition, and brain: Insights from sign language research. Hillsdale: Lawrence Erlbaum.

Everett, C., D. E. Blasi and S. G. Roberts. 2015. Climate, vocal folds, and tonal languages: Connecting the physiological and geographic dots. Proceedings of the $\mathrm{Na}$ tional Academy of Sciences 112(5). 1322-1327.

Fay, N., M. Arbib and S. Garrod. 2013. How to bootstrap a human communication system. Cognitive Science 37. 1356-1367.

Fay, N., C. J. Lister, M. T. Ellison and S. Goldin-Meadow. 2014. Creating a communication system from scratch: Gesture beats vocalization hands down. Frontiers in Psychology 5. 354. DOI: 10.3389/fpsyg.2014.00354.

Ferretti, F., I. Adornetti, A. Chiera, E. Cosentino and S. Nicchiarelli. 2018. "Introduction: Origin and evolution of language - An interdisciplinary perspective. Topoi 37(2). 219-234.

Fitch, T. W. 2010. The evolution of language. Cambridge: Cambridge University Press.

Fitch, T. W. 2017. Empirical approaches to the study of language evolution. Psychonomic Bulletin \& Review 24(1). 3-33.

Fröhlich, M., C. Sievers, S. Townsend, T. Gruber and C. van Schaik. 2019. Multimodal communication and language origins: Integrating gestures and vocalizations. Biological Reviews 94(5). 1-21.

Furness, W. H. 1916. Observations on the mentality of chimpanzees and orangutans. Proceedings of the American Philosophical Society 55. 281-290.

Galantucci, B. 2009. Experimental semiotics: A new approach for studying communication as a form of joint action. Topics in Cognitive Science 1(2). 393-410.

Galantucci, B. 2017. Experimental semiotics. Oxford Research Encyclopedia of Linguistics.

Galantucci, B., S. Garrod and G. Roberts. 2012. Experimental semiotics. Language and Linguistics Compass 6(8). 477-493.

Gärdenfors, P. 2017. Demonstration and pantomime in the evolution of teaching. Frontiers in Psychology 8. 415. 
Gardner, R. A. and B. T. Gardner. 1969. Teaching sign language to a chimpanzee. Science 165. 664-672.

Garrod, S., N. Fay, J. Lee, J. Oberlander and T. MacLeod. 2007. Foundations of representation: where might graphical symbol systems come from? Cognitive Science 31(6). 961-987.

Gibson, E., S. T. Piantadosi, K. Brink, L. Bergen, E. Lim and R. Saxe. 2013. A noisychannel account of crosslinguistic word-order variation. Psychological Science 24(7). 1079-1088.

Goldin-Meadow, S. and C. Mylander. 1998. Spontaneous sign systems created by deaf children in two cultures. Nature 391(6664). 279.

Goldin-Meadow, S. 2008. Gesture, speech, and language. In: A. Smith, K. Smith and R. Ferrer-i-Cancho (eds.), Proceedings of the 7th International Conference on the Evolution of Language. 427-428. London: World Scientific.

Hall, E. 1969. The hidden dimension. New York: Doubleday.

Hall, E. 1976. Beyond culture. New York: Anchor Press.

Hall, M. L., R. I. Mayberry and V. S. Ferreira. 2013. Cognitive constraints on constituent order: Evidence from elicited pantomime. Cognition 129(1). 1-17.

Harnad, S. 1990. The symbol grounding problem. Physica D: Nonlinear Phenomena 42(1-3). 335-346.

Hauser, M. D., N. A. Chomsky and W. T. Fitch. 2002. The faculty of language: What is it, who has it, and how did it evolve? Science 298. 1569-1579.

Hayes, K. J. and C. Hayes. 1952. Imitation in a home-raised chimpanzee. Journal of Comparative and Physiological Psychology 45. 450-459.

Heine, B. and T. Kuteva. 2007. The genesis of grammar: A reconstruction. Oxford: Oxford University Press.

Hewes, G. W. 1973. Primate communication and the gestural origin of language. Current Anthropology 14(1-2). 5-24.

Hewes, G. W. 1976. The current status of the gestural theory of language origin. Annals of the New York Academy of Sciences 280(1). 482-504.

Hewes, G. W. 1977. A model for language evolution. Sign Language Studies 15. $97-$ 168.

Hewes, G. W. 1983. The communicative function of palmar pigmentation in man. Journal of Human Evolution 12(3). 297-303.

Hewes, G. W. 1996. A history of the study of language origins and the gestural primacy hypothesis. In A. Lock and C. R. Peters (eds.), Handbook of human symbolic evolution. 263-269. Oxford: Oxford University Press.

Hockett, C. F. 1958. A course in modern linguistics. New York: Macmillan.

Hockett, C. F. 1959. Animal 'languages' and human language. Human Biology 31. 32 39.

Hockett, C. F. 1960a. The origin of speech. Scientific American 203. 88-111.

Hockett, C. F. 1966. The problem of universals in language. In J. Greenberg (ed.), Universals of language. 1-29. Cambridge, MA: The MIT Press.

Hockett, C. F. 1977 (1960). Logical considerations in the study of animal communication. The view from language: Selected essays 1948-1974. 124-162. Athens: The University of Georgia Press. 
Hockett, C. F and S. A. Altmann. 1968. A note on design features. In T. Sebeok (ed.), Animal communication: Techniques of study and results of research. Bloomington: Indiana University Press. 61-72.

Humboldt, W. von. 1999 (1836). On language: On the diversity of human language construction and its influence on the mental development of the human species. Trans. P. Heath. Cambridge: Cambridge University Press.

Hurford, J. R. 1989. Biological evolution of the Saussurean sign as a component of the language acquisition device. Lingua 77(2). 187-222.

Hurford, J. R. 1999. The evolution of language and languages. In R. Dunbar, C. Knight and C. Power (eds.), The evolution of culture. 173-193. Edinburgh: Edinburgh University Press.

Hurford, J. R. 2003. The language mosaic and its evolution. In M. H. Christiansen and S. Kirby (eds.), Language evolution: The states of the art. 38-57. Oxford: Oxford University Press.

Hurford, J. 2012. The origins of grammar: Language in the light of evolution II. Oxford: Oxford University Press.

Imai, M. and S. Kita. 2014. The sound symbolism bootstrapping hypothesis for language acquisition and language evolution. Philosophical Transactions of the Royal Society B: Biological Sciences 369(1651). 20130298.

Irvine, E. 2016. Method and evidence: gesture and iconicity in the evolution of language. Mind \& Language 31(2). 221-247.

Jackendoff, R. 2002. Foundations of Language. Brain, Meaning, Grammar, Evolution. New York: Oxford University Press.

Jespersen, O. 1922. Language: Its nature, origin and development. London: Allen and Unwin.

Kegl, J., A. Senghas and M. Coppola. 1999. Creation through contact: Sign language emergence and sign language change in Nicaragua. In M. DeGraff(ed.), Language creation and language change: Creolization, diachrony and development. 179-237. Cambridge, MA: MIT Press.

Kellogg, W. N. and L. A. Kellogg. 1933. The ape and the child: A comparative study of the environmental influence upon early behavior. New York: Hafner.

Kendon, A. 1967. Some functions of gaze direction in social interaction. Acta Psychologica 26. 22-63.

Kendon, A. 1991. Some considerations for a theory of language origins. Man 26. 199221.

Kendon, A. 2004. Gesture: Visible action as utterance. Cambridge: Cambridge University Press

Kendon, A. 2011. Some modern considerations for thinking about language evolution: A discussion of the Evolution of language by Tecumseh Fitch. The Public Journal of Semiotics 3(1). 79-108.

Kendon, A. 2014. The 'poly-modalic' nature of utterances and its relevance for inquiring into language origins. In D. Dor, C. Knight and J. Lewis (eds.), The social origins of language. 67-76. Oxford: Oxford University Press.

Kendon, A. 2017. Reflections on the gesture-first hypothesis of language origins. Psychonomic Bulletin \& Review 24(1). 163-170. 
Kirby, S. 2000. Syntax without natural selection: How compositionality emerges from vocabulary in a population of learners. In C. Knight, J. Hurford and M. StuddertKennedy (eds.), The evolutionary emergence of language: Social function and the origins of linguistic form. 303-323. Cambridge: Cambridge University Press.

Kirby, S. 2017. Culture and biology in the origins of linguistic structure. Psychonomic Bulletin \& Review 24(1). 118-137.

Kirby, S. and J. Hurford. 2002. The emergence of linguistic structure: An overview of the Iterated Learning Model. In A. Cangelosi and D. Parisi (eds.), Simulating the evolution of language. London: Springer-Verlag. 121-148.

Kirby, S., H. Cornish and K. Smith. 2008. Cumulative cultural evolution in the laboratory: An experimental approach to the origins of structure in human language. Proceedings of the National Academy of Sciences 105(31). 10681-10686.

Kirby, S., M. Tamariz, H. Cornish and K. Smith. 2015. Compression and communication in the cultural evolution of linguistic structure. Cognition 141. 87-102.

Kita, S., M. Alibali and M. Chu. 2017. How do gestures influence thinking and speaking? The gesture-for-conceptualization hypothesis. Psychological Review 124(3). 245.

Kita, S. and A. Özyürek. 2003. What does cross-linguistic variation in semantic coordination of speech and gesture reveal?: Evidence for an interface representation of spatial thinking and speaking. Journal of Memory and Language 47. 16-32.

Lakoff, G. 1987. Women, fire and dangerous things. Chicago: University of Chicago Press.

Lakoff, G. and M. Johnson. 1980. Metaphors we live by. Chicago: University of Chicago Press.

Lakoff, G. and M. Turner. 1989. More than cool reason: A field guide to poetic metaphor. Chicago: University of Chicago Press.

Lepic, R., C. Börstell, G. Belsitzman and W. Sandler. 2016. Taking meaning in hand. Sign Language \& Linguistics 19(1). 37-81.

Levinson, S. 2006. On the human "interaction engine". In N. Enfield and S. C. Levinson (eds.), Roots of human sociality: Culture, cognition and interaction. 39-69. Oxford: Berg.

Lewin, R. and R. A. Foley. 2004. Principles of human evolution. (2nd edition.) Oxford: Blackwell.

Lipowska, D. 2016. Komputerowe modelowanie ewolucji języka [Computer-based modeling of language evolution]. Poznań: Wydawnictwo Naukowe UAM.

Lockwood, G. and M. Dingemanse. 2015. Iconicity in the lab: A review of behavioral, developmental and neuroimaging research into sound-symbolism. Frontiers in Psychology 6. 1246.

Lupyan, G. and R. Dale. 2010. Language structure is partly determined by social structure. PLoS ONE 5.1. e8559.

Lyell, C. 1930. Principles of geology. London: John Murray.

MacKeigan, T. and S. Q. Muth. 2006. A grammatical network of Tzotzil-Mayan colour terms. Progress in Colour Studies: Language and Culture 1. 25-36.

MacNeilage, P. F. 2008. The origin of speech. Oxford: Oxford University Press. 
Meir, I., A. Lifshitz, D. Ilkbasaran and C. A. Padden. 2010. The interaction of animacy and word order in human languages: A study of strategies in a novel communication task. Proceedings of the Eighth Evolution of Language Conference, 455-456.

Meir, I., W. Sandler, C. Padden and M. Aronoff. 2010. Emerging sign languages. In M. Marschark and and P. E. Spencer (eds.), Oxford handbook of deaf studies, language and education (vol. 2). 267-280. Oxford: Oxford University Press.

McNeill, D. 1992. What gestures reveal about thought. Chicago: The University of Chicago Press.

McNeill, D. 2005. Gesture and thought. Chicago: The University of Chicago Press.

McNeill, D. 2012. How language began: Gesture and speech in human evolution. Cambridge: Cambridge University Press.

Mithen, S. J. 2005. The singing Neanderthals: The origins of music, language, mind and body. London: Weidenfeld and Nicholson.

Monaghan, P., R. C. Shillcock, M. H. Christiansen and S. Kirby. 2014. How arbitrary is language? Philosophical Transactions of the Royal Society B: Biological Sciences 369(1651). p.20130299.

Morford, J. P. and J. A. Kegl. 2000. Gestural precursors to linguistic constructs: how input shapes the form of language. In D. McNeill (ed.), Language and gesture. 358387. Cambridge: Cambridge University Press.

Motamedi-Mousavi, Y., M. Schouwstra, J. Culbertson, K. Smith and S. Kirby. 2017. The cultural evolution of complex linguistic constructions in artificial sign languages. Proceedings of the 39th Annual Conference of the Cognitive Science Society. Cognitive Science Society.

Napoli, D. J. and R. Sutton-Spence. 2014. Order of the major constituents in sign languages: Implications for all language. Frontiers in Psychology 5.376.

Newmeyer, F. J. 2002. "17 uniformitarian assumptions and language evolution research. The Transition to Language 2. 359-375

Ohala, J. J. 1983. The origin of sound patterns in vocal tract constraints. In P. F. MacNeilage (ed.), The production of speech. New York: Springer. 189-216.

Ortega, G. and A. Özyürek. 2019. Systematic mappings between semantic categories and types of iconic representations in the manual modality: A normed database of silent gesture. Behavior Research Methods 52. 51-67.

Orzechowski, S., S. Wacewicz and P. Żywiczyński. 2016. Problem 'zmiany modalności’ w hipotezach pierwszeństwa gestów w ewolucji języka: W stronę hipotez multimodalnych [The problem of 'modality change' in gesture primacy hypotheses of language evolution: Towards multimodal hypotheses]. Studia Semiotyczne 27$28,335-369$.

Padden, C., I. Meir, M. Aronoff and W. Sandler. 2010. The grammar of space in two new sign languages. In: D. Brentari (ed.), Sign languages. 570-592. Cambridge: Cambridge University Press.

Patterson, F. G. P. and M. L. Matevia. 2001. Twenty-seven years of Project Koko and Michael. In M. F. G. Biruté et al. (eds.), All apes great and small: African apes. 165-176. New York: Springer.

Perlman, M. 2017. Debunking two myths against vocal origins of language. Interaction Studies 18(3). 376-401. 
Perlman, M., R. Dale and G. Lupyan. 2015. Iconicity can ground the creation of vocal symbols. Royal Society Open Science 2(8). 150-152.

Pika, S. and K. Liebal. 2006. Differences and similarities between the natural gestural communication of the great apes and human children. In A. Cangelosi, A. Smith and K. Smith (eds.), Proceedings of the 6th International Conference on the Evolution of Language (Evolang 6). 267-274. Singapore: World Scientific.

Pomerantz, A. 1984. Agreeing and disagreeing with assessments: Some features of preferred and dispreferred turn shapes. In J. M. Atkinson and J. Heritage (eds.), Structures of social action. Studies in conversation analysis. 57-101. Cambridge: Cambridge University Press.

Premack, D. and A. Premack. 1974. Teaching visual language to apes and languagedeficient persons. In R. Schiefelbusch and L. Lloyd. (eds.), Language perspectives: Acquisition, retardation and intervention. 347-375. Baltimore: University Park Press.

Pyers, J. E., A. Shusterman, A. Senghas, E. S. Spelke and K. Emmorey. 2010. Evidence from an emerging sign language reveals that language supports spatial cognition. Proceedings of the National Academy of Sciences 107(27). 12116-12120.

Roberts, S. and J. Winters. 2012. Social structure and language structure: The new nomothetic approach. Psychology of Language and Communication 16(2). 89-112.

Sacks, H. and E. A. Schegloff. 1973. Opening up closings. Semiotica 8(4). 289-327.

Sandler, W., I. Meir, C. Padden and M. Aronoff. 2005. The emergence of grammar: Systematic structure in a new language. Proceedings of the National Academy of Sciences, 102(7). 2661-2665.

Sandler, W. 2013. Vive la Différence: Sign language and spoken language in language evolution. Language and Cognition 5(2-3). 189-203.

Saussure, F., de. 1960 (1916). Cours de linguistique générale. Paris: Payot.

Savage-Rumbaugh, S., D. Rumbaugh and S. Boysen. 1978. Symbolic communication between two chimpanzees (Pan troglodytes). Science 201(4356). 641-644.

Savage-Rumbaugh, S., J. Scanlon and D. Rumbaugh. 1980. Communicative intentionality in the chimpanzee. The Behavioral and Brain Sciences 3. 620-623.

Schegloff, E. A. 1996. Turn organization: One intersection of grammar and interaction. In: E. Ochs, E. A. Schegloff and S. Thompson (eds.), Interaction and grammar. 52133. Cambridge: Cambridge University Press.

Scott, D. A., R. Carmi, K. Elbedour, G. M. Duyk, E. M. Stone and V. C. Sheffield. 1995. Nonsyndromic autosomal recessive deafness is linked to the DFNB1 locus in a large inbred Bedouin family from Israel. American Journal of Human Genetics 54(4). 965-968.

Scott-Phillips, T. 2010. Evolutionary psychology and the origins of language. Journal of Evolutionary Psychology 8(4). 289-307.

Senghas, A. and M. Coppola. 2001. Children creating language: How Nicaraguan Sign Language acquired a spatial grammar. Psychological Science 12(4). 323-328.

Senghas A., K. Sotaro and A. Özyürek. 2004. Children creating core properties of language: Evidence from an emerging sign language in Nicaragua. Science 305(5691). 1779-1782. 
Skirgård, H., S. Roberts and L. Yencken. 2017. Why are some languages confused for others? Investigating data from the Great Language Game. PloS oOne 12(4). e0165934.

Slocombe, K. 2011. Have we underestimated great ape vocal capacities? In M. Tallerman and K. R. Gibson (eds.), The Oxford handbook of language evolution. 90-95. Oxford: Oxford University Press.

Smith, K., S. Kirby and H. Brighton. 2003. Iterated learning: A framework for the emergence of language. Artificial Life 94. 371-386.

Stamp R. and W. Sandler. 2016. The grammar of the body and the emergence of complexity in sign languages. In S. Roberts, C. Cuskley, L. McCrohon, L. BarcelóCoblijn, O. Fehér and T. Verhoef (eds.), The evolution of language: Proceedings of the 11th International Conference (EVOLANG11). Available online: $<\mathrm{http}$ ://evolang.org/neworleans/papers/81.html>

Steels, L. 2006. The Talking Heads experiment and cognitive philosophy. A tutorial accompanying the presentation in Current Issues PART II - The Talking Heads experiment. Gideon Borensztajn, Vidhi Trehan, UvA.

Steels, L. 2012. Grounding language through evolutionary language games. In L. Steels, and M. Hild (eds.), Language grounding in robots. 1-22. Boston: Springer.

Steels, L. 2015. The Talking Heads experiment. Origins of words and meanings. Berlin: Language Science Press.

Stokoe, W. 1960. Sign language structure. Silver Spring: Linstok.

Stokoe, W. 2001. Language in hand: Why sign came before speech. Washington, DC: Gallaudet University Press.

Swadesh, M. 1971. The origin and diversification of language. Chicago: Alidne \& Atherton.

Tamariz, M., S. Roberts, J. Martínez and J. Santiago. 2018. The interactive origin of iconicity. Cognitive Science 42(1). 334-349.

Tomasello, M. 1999. The human adaptation for culture. Annual Review of Anthropology 28. 509-529.

Tomasello, M. 2008. Origins of human communication. Cambridge, MA: MIT Press.

Torreira, F., S. Bögels and S. Levinson. 2015. Breathing for answering: The time course of response planning in conversation. Frontiers in Psychology 6. 284.

Trudgill, P. 2002. Linguistic and social typology. In J. K. Chambers, P. Trudgill and N. Schilling-Estes (eds.), The handbook of language variation and change. 707-728. Oxford: Blackwell.

Vigliocco, G., P. Perniss and D. Vinson. 2014. Language as a multimodal phenomenon: Implications for language learning, processing and evolution. Philosophical Transactions of the Royal Society B 369(1651). 20130292.

Wacewicz, S. and P. Żywiczyński. 2015. From the narrow to the broad. Multiple perspectives on language evolution. Theoria et Historia Scientiarum 11. 5-18.

Winters, J., S. Kirby and K. Smith. 2015. Languages adapt to their contextual niche. Language and Cognition 7(3). 415-449.

Wray, A. 1998. Protolanguage as a holistic system for social interaction. Language and Communication 18(1). 47-67. 
Wray, A. and G. W. Grace. 2007. The consequences of talking to strangers: Evolutionary corollaries of socio-cultural influences on linguistic form. Lingua 117(3). 543578.

Zlatev, J. 2008. From proto-mimesis to language: Evidence from primatology and social neuroscience. Journal of Physiology - Paris 102(1-3). 137-151.

Zlatev, J., S. Wacewicz, P. Żywiczyński and J. van de Weijer. 2017. Multimodal-first or pantomime-first? Communicating events through pantomime with and without vocalization. Interaction Studies 18. 465-488.

Żywiczyński, P., N. Gontier and S. Wacewicz. 2017. The evolution of (proto-)language: Focus on mechanisms. Language Sciences 63. 1-11.

Żywiczyński, P. 2018. Language origins: From mythology to science. Berlin: Peter Lang.

\section{Internet sources}

Ethnologue. Available online: <http://www.ethnologue.com>. (20 Jul 2019)

Stanford Encyclopedia of Philosophy. Bayes' theorem. Available online: $<$ https://plato.stanford.edu/entries/bayes-theorem/>. (20 Jul 2019)

The Human Genome Project. 1990-2003. Available online: $<$ https://web.ornl.gov/sci/techresources/Human_Genome/>. (20 Jul 2019)

World Atlas of Linguistic Structures. Available online: $<$ http://www.wals.info $>$. (20 Jul 2019)

\section{Corresponding author:}

Przemysław Żywiczyński

Centre for Language Evolution Studies

Faculty of Languages

Nicolaus Copernicus University

Collegium Maius

Fosa Staromiejska 3

87-100 Toruń

Poland

przemek@umk.pl 